\title{
Flow Improvement in Rectangular Air Intake by Submerged Vortex Generators
}

\author{
A. R. Paul ${ }^{1 \dagger}$, K. Kuppa ${ }^{2}$, M. S. Yadav ${ }^{3}$ and U. Dutta ${ }^{2}$ \\ ${ }^{1}$ Lecturer, Department of Applied Mechanics, M. N. National Institute of Technology, Allahabad, India \\ ${ }^{2}$ Graduate Student, Department of Mechanical Engineering, M. N. National Institute of Technology, Allahabad, India \\ ${ }^{3}$ Post Graduate Student, Department of Applied Mechanics, M. N. National Institute of Technology, Allahabad, India
}

†Corresponding Author Email: arpaul2k@yahoo.co.in

(Received mmmm dd, yyyy; accepted mmmm dd, yyyy)

\begin{abstract}
Rectangular S-duct diffusers are widely used in air-intake system of several military aircrafts. A well-designed diffusing duct should efficiently decelerate the incoming flow, over a wide range of incoming conditions, without the occurrence of streamwise separation. A short duct is desired because of space constraint and aircraft weight consideration, however this results in the formation of a secondary flow to the fluid within the boundary layer. The axial development of these secondary flows, in the form of counter rotating vortices at the duct exit is responsible for flow non-uniformity and flow separation at the engine face. Investigation on S-shaped diffusers reveals that the flow at the exit plane of diffusers is not uniform and hence offers an uneven impact loading to the downstream components of diffuser. Experiments are conducted with an S-shaped diffuser of rectangular cross-section at $R e=1.34 \times 10^{5}$ to find out the effects of the corners (i.e. sharp $90^{\circ}, 45^{\circ}$ chamfered etc.) on its exit flow pattern. A 'fishtail' shaped submerged vortex generators (VG) are designed and introduced at different locations inside the diffusers in multiple numbers to control the secondary flow, thereby improving the exit flow pattern. It is found that the locations of the VG have a better influence on the flow pattern rather than the number of the VG used. The best combination examined in this study is a $45^{\circ}$ chamfered duct with $3 \times 3 \mathrm{VG}$ fixed at the top and bottom of the duct inflexion plane. The results exhibit a marked improvement in the performance of S-duct diffusers. Coefficient of static pressure recovery $\left(C_{\mathrm{SP}}\right)$ and coefficient of total pressure loss $\left(C_{\mathrm{TL}}\right)$ for the best configuration are reported as $48.57 \%$ and $3.54 \%$ respectively. With the best configuration of $\mathrm{VG}$, the distortion coefficient $\left(D C_{60}\right)$ is also reduced from 0.168 (in case of bare duct) to 0.141 .
\end{abstract}

Keywords: S-duct diffuser, Three-hole pressure probe, Passive flow control, Submerged vortex generator, Static pressure recovery, Total pressure loss, Distortion coefficient.

\section{NOMENCLATURE}

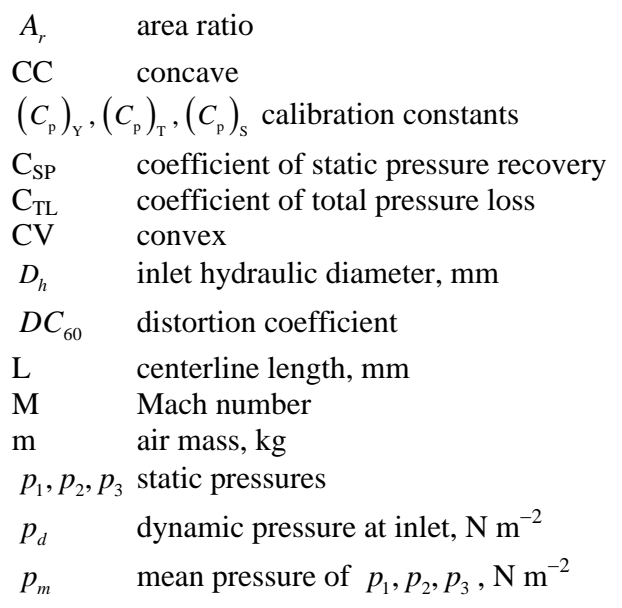

$\begin{array}{ll}p_{\mathrm{T} i} & \text { total pressure at inlet, } \mathrm{N} \mathrm{m}^{-2} \\ p_{60} & \text { total pressure in the worst } 60^{\circ} \text { sector } \\ R_{c} & \text { radius of curvature, } \mathrm{mm} \\ \mathrm{Re} & \text { Reynolds number at inlet, dimensionless } \\ \mathrm{r} & \text { Radial distance from centerline, } \mathrm{m} \\ \mathrm{U} & \text { mass averaged inlet velocity, } \mathrm{m} \mathrm{s}^{-1} \\ \mathrm{u} & \text { velocity, } \mathrm{m} \mathrm{s}^{-1} \\ u_{x}, u_{y} & \text { velocity components, } \mathrm{m} \mathrm{s}^{-1} \\ \alpha & \text { pitch angle } \\ \beta & \text { yaw angle } \\ \Delta \beta & \text { centerline curvature, degree } \\ \delta & \text { boundary layer thickness,mm } \\ \mu & \text { dynamic viscosity coefficient, } \mathrm{N} \mathrm{s} \mathrm{m}^{-2} \\ v & \text { kinematic viscosity coefficient, } \mathrm{m} \mathrm{s}^{2} \mathrm{~s}^{-1}\end{array}$




$$
\begin{array}{ll}
p_{\mathrm{S}} & \text { static pressure, } \mathrm{N} \mathrm{m}^{-2} \\
p_{\mathrm{S} i} & \text { static pressure at inlet, } \mathrm{N} \mathrm{m}^{-2} \\
p_{\mathrm{T}} & \text { total pressure, } \mathrm{N} \mathrm{m}^{-2} \\
p_{\mathrm{T} e} & \text { total pressure at exit, } \mathrm{N} \mathrm{m}^{-2}
\end{array}
$$

\section{INTRODUCTION}

An S-shaped diffusing duct is an essential feature of a combat aircraft intake system. The major challenge of air-intake design is to ensure that an aircraft engine is properly supplied with air under all conditions of aircraft operation and that the aptitude of the airframe is not unduly impaired in the process (Seddon et al. 1999). The basic shape of the duct is important since an engine requires air at a moderate subsonic speed i.e., at a speed lower than the aircraft flying speed at the front part of the duct, which is achieved in the form of a diffuser. The primary purpose of the S-duct is to convey air from the wing or fuselage intake to the engine compressor. Further, it decelerates flow velocity and subsequently increases pressure head from kinetic energy head along its length. The diffusion phenomenon is the conversion of kinetic energy of the fluid into pressure energy in the direction of flow. Amongst the military aircrafts, F-16, F-18, light combat aircrafts (LCA) and many others use S-ducts in their air-intake system.

A well-designed diffusing duct should efficiently decelerate the incoming flow, over a wide range of incoming conditions, without the occurrence of stream wise flow separation. A short duct is desired because of space constraint and aircraft weight consideration, resulting in high degrees of centerline curvature. The centerline curvature gives rise to streamline curvature causing cross-stream pressure gradients. These crossstream pressure gradients impart a transverse or cross flow velocity, known as secondary flow to the fluid within the boundary layer. The axial development of the secondary flow in the form of counter rotating vortices at the duct exit is responsible for a good deal of flow non-uniformity at the engine face. The secondary flow convects the low energy boundary layer fluid from the duct surface to the centre of the duct, creating highly non-uniform cross-stream total pressure profiles. Additionally, stream wise pressure gradients result from diffusing (increasing) cross-sectional area. The combined effect may result in a region of flow separation, leading to increased total pressure nonuniformity (i.e. distortion) and total pressure loss at the duct exit. This flow blockage reduces the total pressure recovery of the duct. The flow conditions emerging from the duct play a key role in the design of the downstream elements like compressor, combustion chamber etc. Instances like engine surging may happen in flight because of a large swirl angle and absence of guide vanes, which leads to compressor stall.

The first systematic study on two-dimensional curved subsonic diffuser has been carried out by Fox and Kline (1962). Around early 1980's, the rapid advancement of modern aircraft engines necessitate the study of Sshaped diffusing ducts to improve the velocity distribution and to tackle the self generated swirl at the

$\begin{array}{ll}\rho & \text { density of fluid, } \mathrm{kg} \mathrm{m}^{-3} \\ \text { subcripts } & \\ \mathrm{S} & \text { static } \\ \mathrm{T} & \text { total } \\ \mathrm{Y} & \text { yaw }\end{array}$

exit of the diffusers. Guo and Seddon (1983) investigated the swirl in an S-duct of typical aircraft intake proportions at different angle incidences. The static pressure recovery $\left(\mathrm{C}_{\mathrm{SP}}\right)$ reduced with the increase in angle of attack $\left(\mathrm{C}_{\mathrm{SP}}=0.89\right.$ at $0^{\circ}$ angle of attack and $\mathrm{C}_{\mathrm{SP}}=0.37$ at $30^{\circ}$ angle of attack) and it could be improved by incorporating several mechanical devices at the inlet, such as, spoiler, fences etc. They studied two methods in order to reduce the magnitude of swirl by means of a spoiler and to re-energize the separated flow with the inflow of free stream air through auxiliary inlets. Stocks \& Bussinger (1981) report the swirl measurements for the tornado intake at $20^{\circ}$ angle of attack for Mach number 0.7 and at $3^{\circ}$ angle of attack for Mach number 1.8 which shows that the swirl reduction is obtainable by the use of duct and curl fences. Lin and Guo (1989) investigate the flow development of an Sshaped rectangular-round diffusing intake with a vortex control device. The diffuser (tested at $30^{\circ}$ and $40^{\circ}$ angle of attack) shows a separate flow region at bottom wall near the throat of the duct. To reduce the separation, a vortex control device is set there that suck out the line vortex. They even recommend the said vortex control method as being effective for removing swirl, decreasing total pressure loss and improving flow-field in S-shaped intake.

Reichert and Wendt (1993) use a low-profile 'wishbone' shaped vortex generator to improve the total pressure distortions and recovery performance of diffusing S-duct. Three characteristic parameters, namely vortex generator height, stream wise location of the vortex generator array, and the vortex generator spacing were systematically are varied to determine their effects. The configuration employing largest vortex generator is most effective in reducing distortion, but did not produce major total pressure recovery. In a further study, Reichert and Wendt (1994, 1996) use tapered-fin vortex generators to control the development of secondary flows. 20 configurations of both co- and counter-rotating arrays of tapered-fin vortex generators are tested to reduce total pressure distortion and to improve the total pressure recovery within an S-shaped diffusing duct. The best configuration tested reduces distortion by $50 \%$ while improving the pressure recovery by $0.5 \%$. In another study, Wendt \& Reichert (1996) report the effects of an ingested vortex on the flow field of a diffusing S-duct ( $\left.\Delta \beta=30^{\circ}, R e=2.6 \times 10^{6}, M=0.6, A_{r}=1.52\right)$. The vortex is generated with a non-rotating eight bladed pinwheel device (stationary) mounted upstream of the diffusing S-duct. The ingested vortex at this location reduces the extent of flow-field separation inside the baseline duct and promotes stronger cross-flow of both the baseline duct with vortex generators. The enhanced cross-flow also strengthens the vortices shed from the vortex generators. Foster et al. (1997) conduct flow measurements through a rectangular-to-semi-annular 
transition duct having $A_{r}=1.53$ to demonstrate the efficacy of vortex generators to reduce the circumferential total pressure distortion. Sullerey and his co-researchers (2002) perform experiments to study the effect of various fences and vortex generator configurations in reducing the exit flow distortion and improving the total pressure recovery in twodimensional rectangular S-duct diffusers. It is observed that the fence height and tapered fin vortex generators orientation giving the best performance would vary depending upon the centerline curvature. Fences perform better when used with diffusers of greater radius ratios, while tapered-fin vortex generators would perform better when used with diffusers of lesser radius ratio. Furthermore, Sullerey et al. $(2004,2006)$ presents the effectiveness of active flow control devices (vortex generator jets) in controlling secondary flows in S-duct diffusers of various cross-sections. For uniform inflow, the use of vortex generator jets result more than a $30 \%$ decrease in total pressure loss and flow distortion coefficients. In combination with passive device (tapered fin vortex generators), the vortex generator jets reduce total pressure loss by about $25 \%$ for distorted inflow conditions.

Of late, Harrison et al. (2007) perform an experimental investigation of boundary layer ingesting (BLI) serpentine engine ducts and the effects of flow control on engine-face total distortion. A simulated ejectorpump based system of fluidic actuators is used to directly manage the diffuser secondary flows. The experimental results show that the computational analysis over-predicts the flow distortion (calculated in terms of $\mathrm{DC}_{60}$ parameter) particularly when there are large-scale vertical structures are present. Motivated from the study conducted by Weng and Guo (1994) to effectively control swirl in S-diffuser with help of an automatic adjustable blade (AAB), very recently, Paul et al. (2008) used a twin-bladed flow deflector at the sigmoid duct's inlet in order to uniform the flow pattern at its exit. Flow pattern claimed to be more uniform at the duct exit with the installation of the flow deflector.

Literature survey on S-shaped diffusers reveals that the flow at the exit plane of diffusers is not uniform and hence offers an uneven impact loading to the downstream components of the diffuser like compressor, combustion chamber etc. From design point of view, it is undesirable. Here, an attempt is made to uniform the flow of the S-diffuser, especially at its exit by changing its corner shapes (i.e. sharp $90^{\circ}, 45^{\circ}$ chamfered etc.) as well as using submerged vortex generators (VG). Lin et al. (1991) conducted an exploratory study of such VG devices to control turbulent flow separation. Such VG produce vortices, which transport high momentum fluid into the boundary layer, making it thinner and more resistant to the adverse pressure gradients with respect to separation. Further study by Lin (2002) found that if the height of the vortex generators are shorter than the boundary layer height $(\delta)$, they can have a larger effect on the downstream flow, since the velocity gradient is quite high and hence are named as 'submerged' vortex generators.
Getting inspired from these studies, 'fishtail' shaped submerged vortex generators are designed (Fig. 3) and are used at different locations inside the diffusers in multiple numbers to control the secondary flow, thereby improving the exit flow pattern. The boundary layer from either side of the walls at inlet grows around 11 $\mathrm{mm}$, thereby for a span of $65 \mathrm{~mm}$ width (or height) at the inlet; a total of $22 \mathrm{~mm}$ is covered with boundary layer. The maximum height of the 'fishtail' shaped submerged vortex generator is kept as $2.6 \mathrm{~mm}$, and hence it is completely submerged within the boundary layer. The following sections describe the effects of corner shapes as well as submerged VG on the flow quality of S-duct diffuser in detail.

\section{EXPERIMENTAL TECHNIQUE}

The experimental set-up consists of an air supply unit, a conical diffuser, a settling chamber, a contraction cone, a small entry duct (reducer) and above all a test diffuser. The conical diffuser and the settling chamber are fabricated from sheet metal (galvanized iron) whereas the contraction cone and the reducer are made up of fiber reinforced plastic (FRP). The complete geometry of the test diffuser along with the coordinate system used is shown in Fig. 1. The diffuser is fabricated from perspex sheet as per the design suggested by Fox and Kline (1962) and based on linear area-ratio from inlet to exit. The inlet size of the test diffuser is chosen as $65 \times 65 \mathrm{~mm}^{2}$. It is designed based on area-ratio $\left(A_{\mathrm{r}}\right)$ of 1.92 with $R_{\mathrm{c}}=280 \mathrm{~mm} \Delta \beta=$ $30^{\circ} / 30^{\circ}$. The curvature ratio $\left(R_{c} / D_{h}\right)$ of the diffuser is calculated as 4.31. As a new method of flow improvement, the corners of the diffuser are chamfered by $45^{\circ}$ from inlet to exit and are shown in Fig. 1 with dimensions.

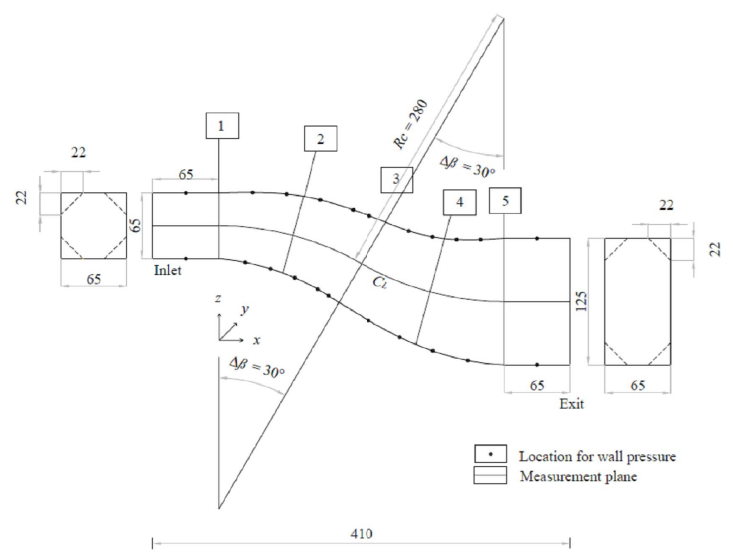

Fig. 1. Schematic diagram of the rectangular S-duct diffuser.

Considering the size and geometry of the test diffusers and optimum accuracy of the results, a digital pressure scanner (make: Furness Control, U.K.) is used to measure pressures at different locations. A telescopic Pitot tube coupled with a digital micromanometer (make: Furness Control, U.K.) is also used to measure free-stream velocity of air. The telescopic Pitot tube has the advantage of convenience and portability over the fixed length Pitot tube. 
In an S-shaped diffuser, the inlet flow condition is mainly affected by the downstream curvature of the diffuser passage. The inlet section, where all inlet conditions are measured is located in the constant area duct, $65 \mathrm{~mm}$ upstream of the diffuser. It is seen that the flow parameters are marginally affected by the downstream curvature and frictional losses in the initial section and it is assumed that the changes due to this curvature and frictional losses are negligible. A straight constant area tailpipe is also introduced at the diffuser exit to improve the flow as well as the performance of the diffusers. The flow rate is maintained constant at the time of experimentation by regulating a throttle valve and simultaneously checking the pressure drop between the inlet and exit of the contraction cone. The inlet freestream velocity (mass averaged) is kept approximately $33 \mathrm{~m} / \mathrm{s}$ corresponds to Reynolds number (Re) $1.34 \times 10^{5}$ based on the diffuser inlet hydraulic diameter $\left(D_{\mathrm{h}}\right)$ of 65 $\mathrm{mm}$ and kinematic viscosity of air as $1.6 \times 10^{-5} \mathrm{Ns} / \mathrm{m}^{2}$ at $30^{\circ} \mathrm{C}$. The inlet free stream dynamic pressure $\left(p_{d}\right)$ corresponding to inlet mass averaged free-stream velocity $(U)$ is held constant at $635 \mathrm{~N} / \mathrm{m}^{2}$ corresponding to air density of $1.23 \mathrm{~kg} / \mathrm{m}^{3}$ at $30^{\circ} \mathrm{C}$. The atmospheric temperature \& pressure are recorded at the time of measurements at each section.

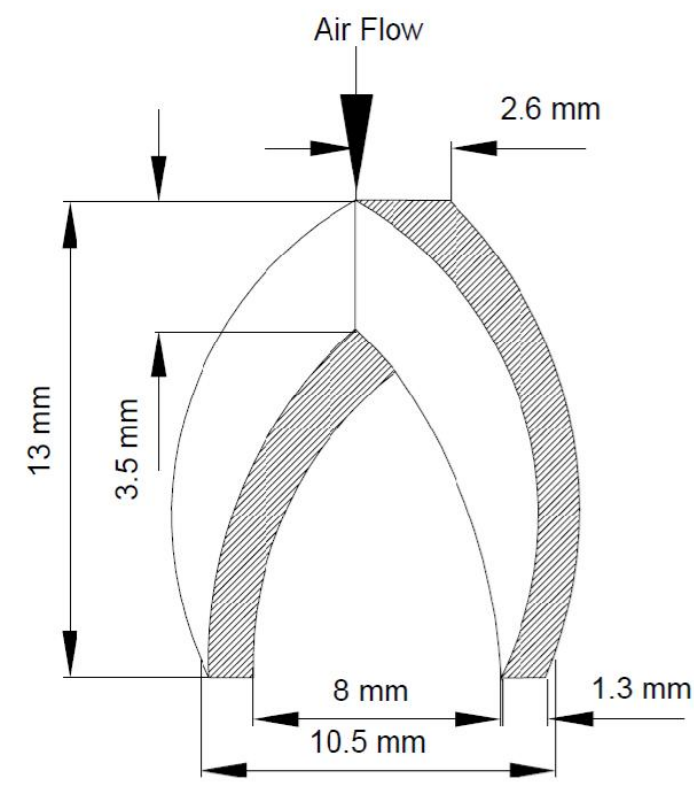

Fig. 2. Three-hole pressure probe

The three-hole probe as shown in Fig. 3 is one of the devices that can be used for this purpose in twodimensional flow field. The three-hole pressure probe combines the means for simultaneous measurement of total pressure, dynamic pressure and mean flow velocity and its direction by one instrument. The use of three-hole probes, although not in plenty are reported in literature. Majumdar (1994) used three-hole probes to measure flow improvement in curved ducts. Bakhtar et al. (2001) studied droplet laden flows with help of three-hole probe and received satisfactory results. Inspired from these studies and because of its simplicity, three-hole probe is used in the present case.
Probe calibration by non-null technique as described in Majumdar (1993) is performed to determine the sensitivity to yaw angles in a known uniform rectilinear flow field.

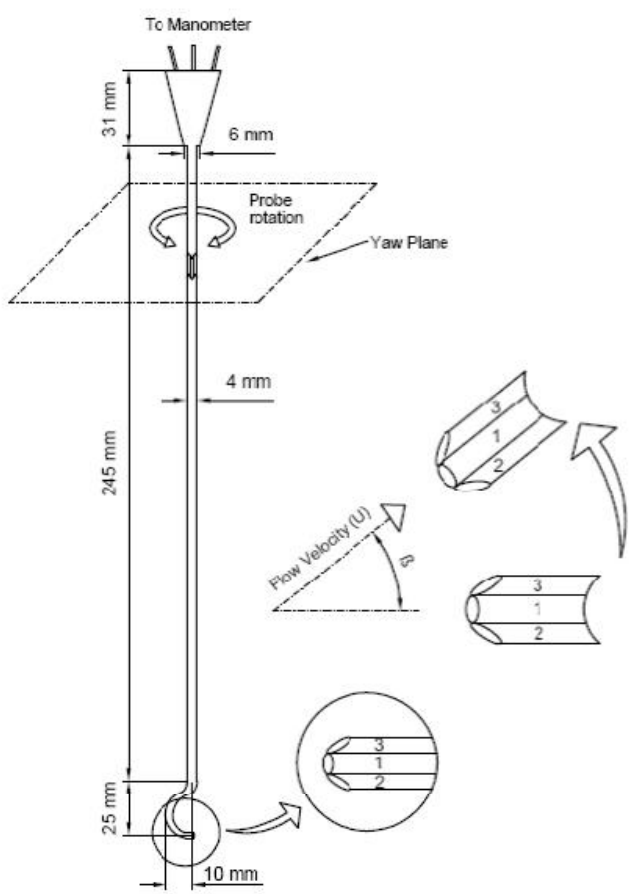

Fig. 3. 'Fishtail' shaped submerged vortex generator

First, the probe is mounted in a fixed position by setting at constant pitch and yaw value with respect to the reference line. Using the probe orientation mechanism, the pitch angle is maintained at $0^{\circ}$ and yaw angle is changed by $5^{\circ}$ increments in a range of $\pm 25^{\circ}$. The static pressures $\left(p_{1}, p_{2}\right.$ and $\left.p_{3}\right)$ sensed from three tubes of the probe are recorded separately for each yaw angle. The calibration constants are then determined by using these static pressures. Calibration constants used in this study are taken from Dominy and Hodson (1993) with necessary simplification for a three-hole probe. These constants are

$$
\begin{aligned}
& \left(C_{\mathrm{p}}\right)_{\text {Yaw }}=\left(C_{\mathrm{p}}\right)_{\mathrm{Y}}=\frac{p_{3}-p_{2}}{p_{1}-p_{\mathrm{m}}}, \quad\left(C_{\mathrm{p}}\right)_{\text {Total }}=\left(C_{\mathrm{p}}\right)_{\mathrm{T}}=\frac{p_{1}-p_{\mathrm{T}}}{p_{1}-p_{\mathrm{m}}}, \\
& \left(C_{\mathrm{p}}\right)_{\text {Static }}=\left(C_{\mathrm{p}}\right)_{\mathrm{S}}=\frac{p_{\mathrm{m}}-p_{\mathrm{S}}}{p_{1}-p_{\mathrm{m}}}
\end{aligned}
$$$$
\text { where, } p_{\mathrm{m}}=\left(p_{1}+p_{2}+p_{3} / 3\right)
$$

The calibration curve is plotted between the calibration constants $\left(C_{\mathrm{p}}\right)_{\mathrm{Y}},\left(C_{\mathrm{p}}\right)_{\mathrm{T}},\left(C_{\mathrm{p}}\right)_{\mathrm{S}}$ and yaw angle $\beta$. The relationship between the calibration constants and yaw angle is described by a second-order polynomial curve fit equations.

During measurement of flow field, the values of $p_{1}, p_{2}$ and $p_{3}$ are measured using the calibrated threehole probe. Now, to find out the flow properties like $\beta, p_{\mathrm{T}}$ and $p_{\mathrm{S}}$; first the value of $\left(C_{\mathrm{p}}\right)_{\mathrm{Y}}$ is measured with help of the known values of $p_{1}, p_{2}$ and $p_{3}$. Next, corresponding to the value of $\left(C_{\mathrm{p}}\right)_{\mathrm{Y}}$, the yaw angle $\beta$ is 
calculated using second-order polynomial equations. Based on the value of $\beta$ found, $p_{\mathrm{T}}$ and $p_{\mathrm{S}}$ can further be calculated.

The relationship between the velocity components $U_{\mathrm{x}}$ and $U_{\mathrm{y}}$ with respect to the $\mathrm{x}$ and y direction in the probe coordinate system and the yaw angle $\beta$ are given below.

$$
U=\sqrt{\left(p_{\mathrm{T}}-p_{\mathrm{S}}\right) \times \frac{2}{\rho}}, \quad U_{\mathrm{x}}=U \cos \beta, U_{\mathrm{y}}=U \sin \beta
$$

All calibration data are repeatable within $\pm 2 \%$ of the inlet free stream dynamic pressure when subjected to recalibration. Wall proximity effects on the probe are also carried out in the presence of sharp-edged flat plate that is mounted parallel to the flow direction. A limitation of two probe diameter (i.e. $5 \mathrm{~mm}$ ) is imposed as the probe is withdrawn through a wall to reduce the wall proximity effects to a great extent. However, since $\left(C_{\mathrm{p}}\right)_{\mathrm{s}}$ affects comparatively more with wall interaction, necessary correction factors are also incorporated in the data reduction program.

\section{RESUltS AND DISCUSSION}

Detailed flow measurement within the bare duct diffuser shows a non-uniform flow pattern at its exit (Figs. 4 and 5). Various methods are employed to uniform the flow pattern at diffuser exit like optimizing the corner geometries of the duct and installing combinations of 'fishtail' vortex generators at different locations within the duct. For each combination, detailed flow quantities, such as, mean velocity, vector plots of secondary velocity, total pressure and static pressure are presented. In this study, the flow characteristics, like, velocity components and pressures are normalized with the inlet mass-averaged velocity and dynamic pressure respectively.
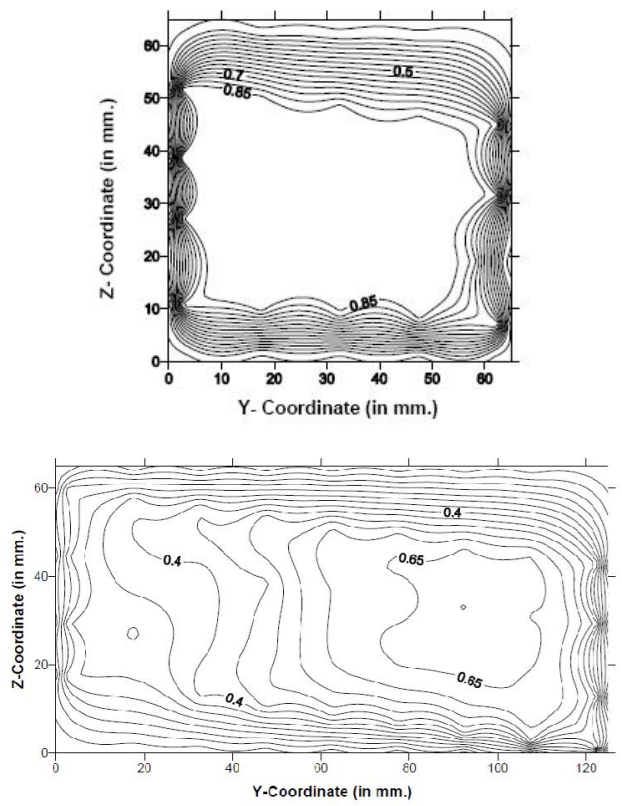

(a) Inlet plane, (b) Exit Plane

Fig. 4. Mean velocity contours for bare duct with sharp $90^{\circ}$ corners.

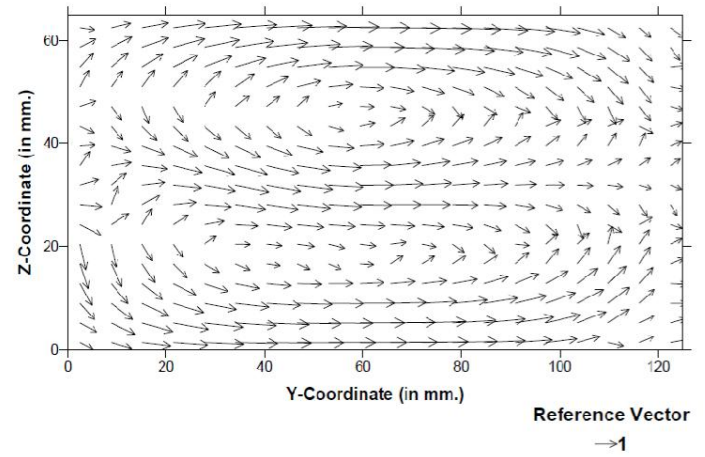

Fig. 4c. Secondary velocity vectors for bare duct with sharp $90^{\circ}$ corners at exit.

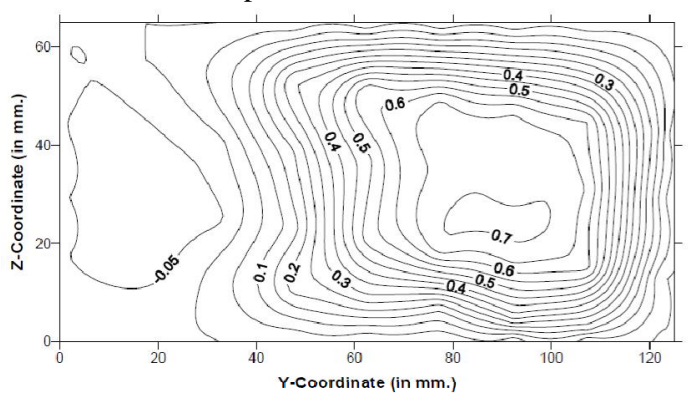

Fig. 4d. Total pressure contours for bare duct with sharp $90^{\circ}$ corners at exit.

\subsection{Flow Investigation through Bare Duct}

The normalized mean velocity contours at five different test sections of the bare duct ranging from inlet to exit are shown in Fig. 4. The corners of the duct remained of sharp $90^{\circ}$ corners and no vortex generator is used. The figure depicts the mean flow, which is diffused from inlet to exit due to increase in cross-sectional area. Due to centerline curvature, a radial imbalance of the centrifugal pressure force $\left(m U^{2} / r\right)$ is set up between the wall-A (CC part) \& wall-B (CV part) and the acceleration produced $\left(U^{2} / r\right)$ acts radially inwards to the duct. Hence, a pressure gradient is set up between these two walls and is responsible for shifting of high velocity fluid from wall-A to wall-B. Mass of flow is shifted from wall-A to wall-B, and hence, a low velocity fluid is accumulated near wall-A (CC part).

The mean flow field in the diffusing curved bend is dominated by a pair of counter-rotating streamwise vortices, which balances the centrifugal force of the fluid as it is diffused and turned. The works reported by Anderson et al. (1982), Whitelaw and Yu (1993), support the above discussion. Figure $4 \mathrm{~b}$ exhibits a distorted flow pattern especially at the bottom wall of the exit plane. The same fact is supported in Fig. 4c since some flow reversals are seen at the exit. Two distinct total pressure zones are reported for bare duct diffuser in Fig. 4d. However, some pressure nonuniformities are seen on the lower portion of the duct exit. For bare duct diffuser, the static pressure contours are shown in Fig. 4e. Here also, two different pressure zones are present. However, the left lobe represents negative static pressure. Some pressure distortions are also noticed at the bottom wall of the exit plane. 


\subsection{Flow Investigation through $90^{\circ}$ Sharp Cornered Diffuser with 'Fishtail' Vortex Generator at Inlet}

To improve the exit flow pattern, 'fishtail' shaped vortex generator (VG) is used as shown in Fig. 3. A pair of VG is fixed at inside of the both top and bottom surface of the inlet (plane-1). The VG are oriented in reverse direction- i.e. its single point faces the upstream of the flow. The VG create counter-rotating vortices of various strengths, which, in turn, interacts with a pair of vortices already available inside the diffuser due to centerline curvature. The combined effect changes the strength as well as the orientation of the vortices, and as a result, the flow pattern at the exit archives better uniformity as compared to the bare duct.

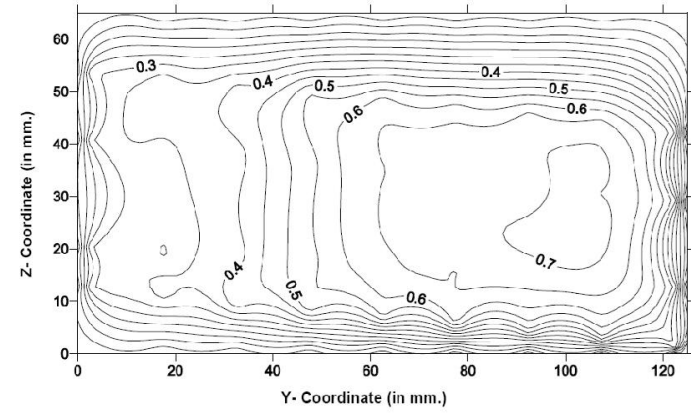

Fig. 5a. Mean velocity contours for bare duct at exit with sharp $90^{\circ}$ corners and 'fishtail' vortex generator installed at inlet.

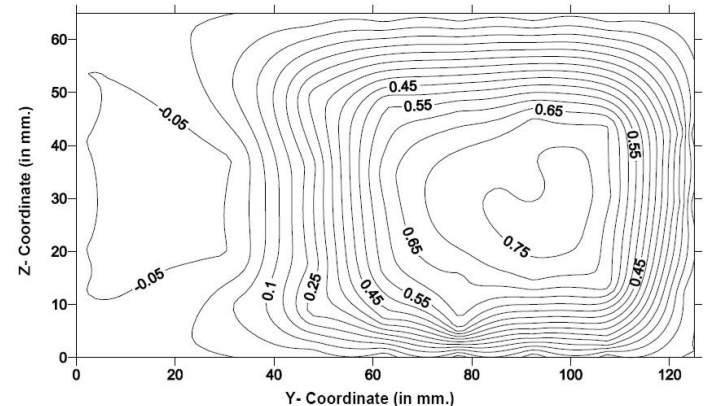

Fig. 5b. Total pressure contours for bare duct at exit with sharp $90^{\circ}$ corners and 'fishtail' vortex generator installed at inlet.

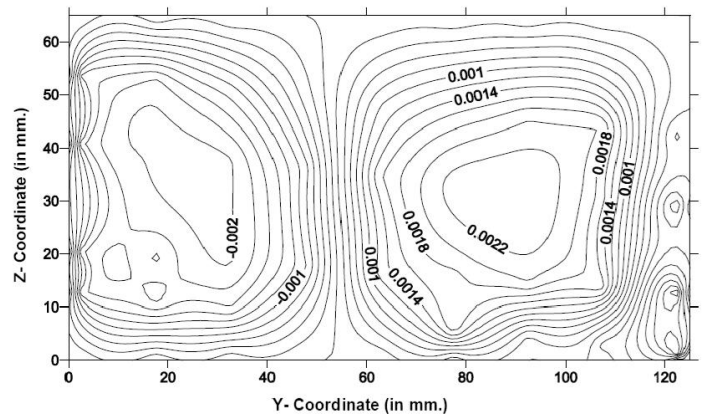

Fig. 5c. Static pressure contours for bare duct at exit with sharp $90^{\circ}$ corners and 'fishtail' vortex generator installed at inlet.

Gross improvement of flows is seen by using two VG at the duct inlet, as the mean velocity contours with $\left(U_{\text {mean }} / U\right)=0.45$ values spread most of the cross- sectional area at the duct exit. Also, the distortion at the bottom plane of the duct exit is now disappeared with the installation of $\mathrm{VG}$ at the duct inlet as shown in Fig. 5a. Total pressure contours as shown in Fig. 5b also supports the fact that the installation of $\mathrm{VG}$ at the duct inlet minimizes the flow distortion. Instabilities are also minimized by using VG at the duct inlet as it is appeared from the static pressure contours (refer to Fig. $5 c)$.

\subsection{Flow Investigation through $45^{\circ}$ Chamfered Diffuser}

A new method of flow improvement is tried just by changing the $90^{\circ}$ sharp corners of the rectangular crosssectioned diffusing duct into $45^{\circ}$ chamfered as shown in Fig. 1. A $23 \%$ of the inlet area is blocked at the inlet (plane-1) by chamfering, which at exit (plane-5) is further reduced to $12 \%$ of the exit area due to area diffusion. The chamfering decreases the effective intake cross-section, thereby reducing the mass flow rate into the engine. However, the method is tried to examine the flow pattern. The mean velocity contours as represented in Fig. 6a shows marked improvement in flow pattern as compared to $90^{\circ}$ sharp cornered diffuser.

No counter-rotating vortex is seen in Fig. 6b. Figure $6 \mathrm{c}$ exhibits a noticeable improvement of total pressure distribution pattern at the duct exit as compared to earlier results (Figs. 4d and 5c). Around half of the duct exit plane is covered by $0.004 p_{d}$ of total pressures. Figure $7 \mathrm{a}$ also supports the fact as described in the previous section.

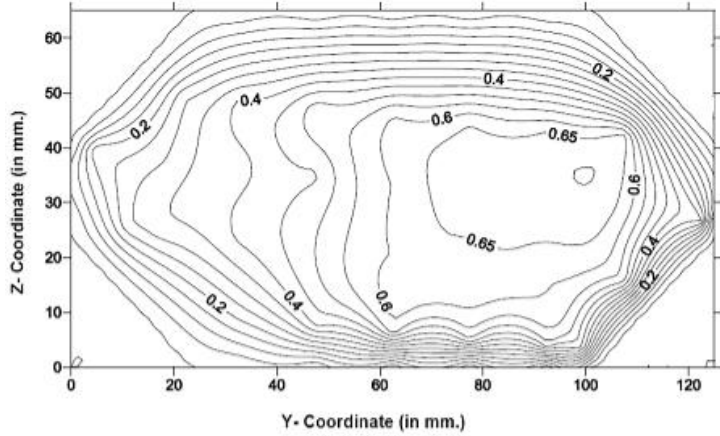

Fig. 6a. Mean velocity contours for $45^{\circ}$ chamfered duct at exit.

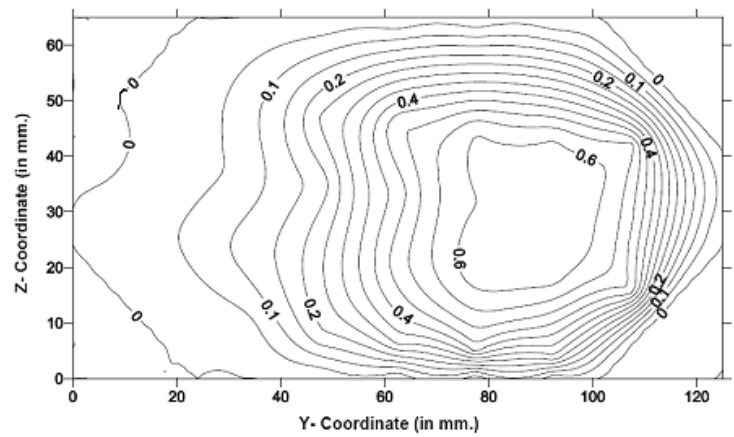

Fig. 6b. Total pressure contours for $45^{\circ}$ chamfered duct at exit. 


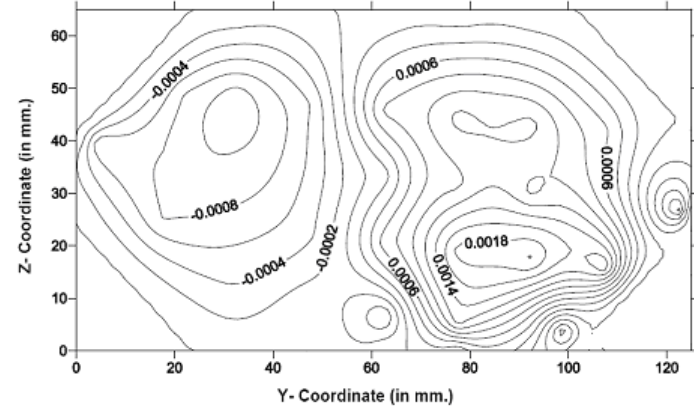

Fig. 6c. Static pressure contours for $45^{\circ}$ chamfered duct at exit.

\subsection{Flow Investigation through $\mathbf{4 5}^{\circ}$ Chamfered Diffuser with 'Fishtail' Vortex Generator at Inlet}

Here two VG are used at the inner walls of top and bottom surfaces of the $45^{\circ}$ chamfered duct. The effects of the chamfered corners and VG installation further complicate the flow and hence, the flow pattern is further deteriorated as compared to bare duct with sharp $90^{\circ}$ corners. There is an increase in the magnitude of normalized mean flow velocity from 0.65 (Fig. 6a) to 0.85 (Fig. 7a). However, flow becomes very much distorted at different locations of the exit plane of the duct. Maximum distortion takes place at the chamfered corners of the duct and is shown in Fig. 7b. Not much improvement of flow is reported in static pressure contours as shown in Fig. 7c. Localized vortices are formed, especially at the chamfered planes of the duct exit.

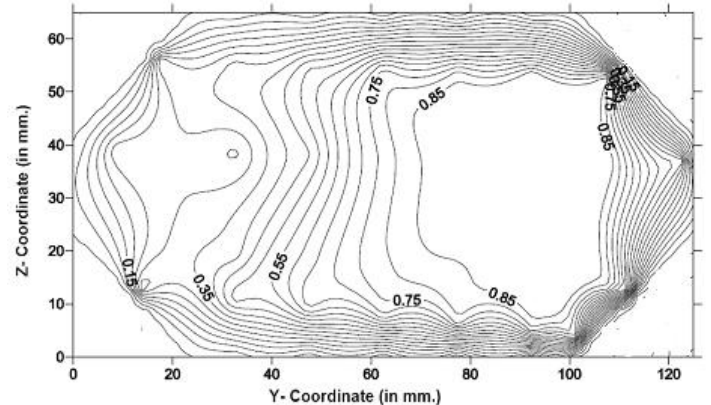

Fig. 7a. Mean velocity contours at exit for $45^{\circ}$ chamfered duct with 'fishtail' vortex generator installed at inlet.

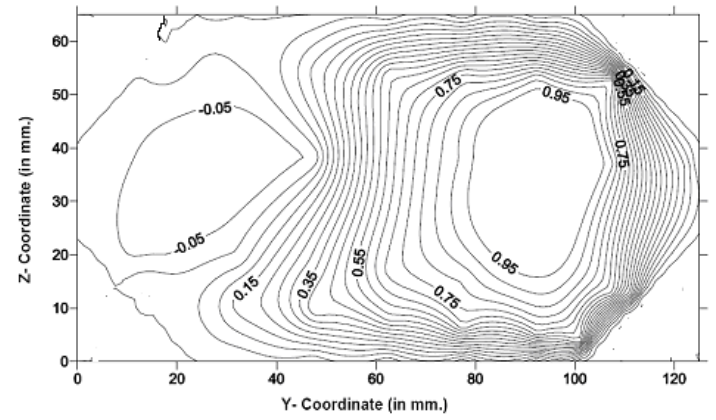

Fig. 7 b. Total pressure contours at exit for $45^{\circ}$ chamfered duct with 'fishtail' vortex generator installed at inlet.

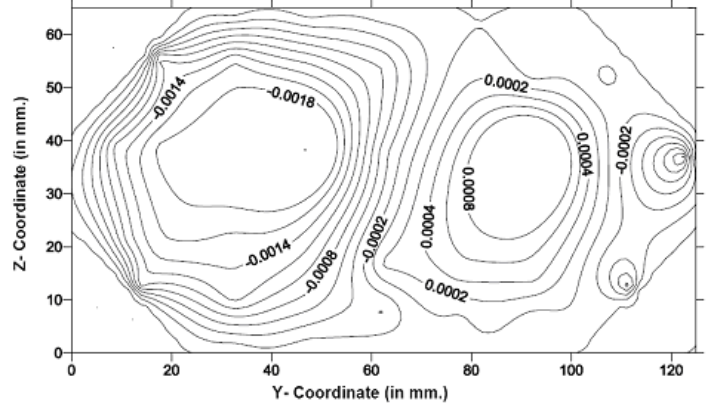

Fig. 7c. Static pressure contours at exit for $45^{\circ}$ chamfered duct with 'fishtail' vortex generator installed at inlet.

\subsection{Flow Investigation through $45^{\circ}$ Chamfered Diffuser with Different 'Fishtail' Vortex Generator Combinations at Various Planes}

Here, for $45^{\circ}$ chamfered diffuser, different combinations of VG are tried- two VG positioning at inlet bottom surface, two each VG locating at both top and bottom inlet surfaces, and finally, three each VG fixed at the top and bottom of the inflexion plane (plane-3). Comparing three combinations as mentioned above, Figs. $8 \mathrm{a}-8 \mathrm{c}$ shows that the velocity pattern is found to be more uniform when using three each VG fixed at the top and bottom of the inflexion plane. The total pressure contours of all three combinations are of similar nature, but magnitude wise, the combinations using three VG each in upper and lower surfaces of the inflexion planes, gives better results (refer to Fig. 8c). ere normalized total pressures increased up to $0.009 P_{\mathrm{dyn}}$

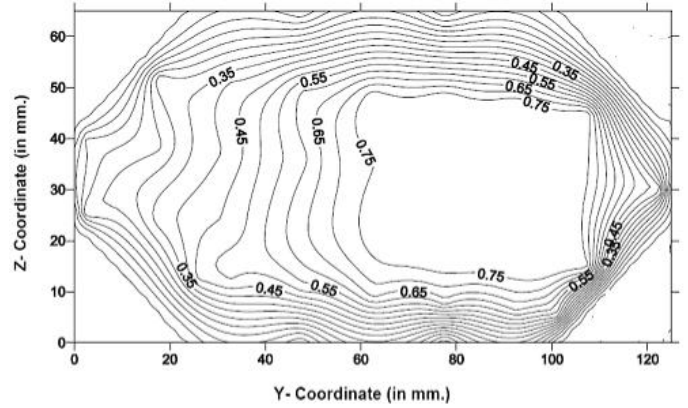

Fig. 8a. Mean velocity contours for chamfered duct with $3 \times 3$ vortex generator at inflexion top and bottom surfaces.

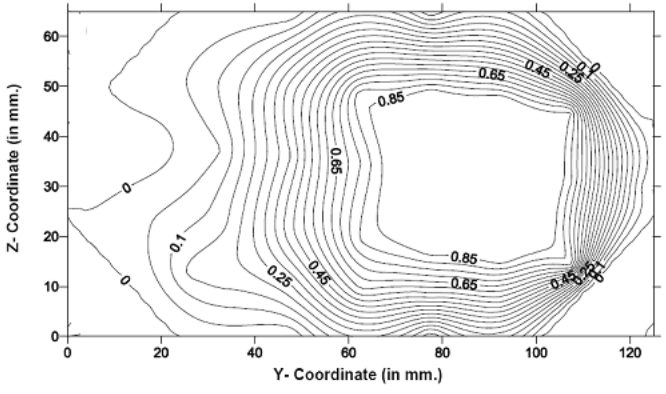

Fig. 8b. Total pressure contours for chamfered duct with $3 \times 3$ vortex generator at inflexion top and bottom surfaces. 


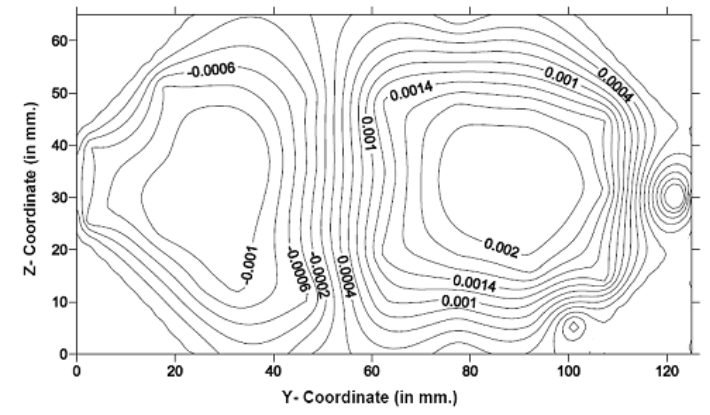

Fig. 8c. Static pressure contours for chamfered duct with $3 \times 3$ vortex generator at inflexion top and bottom surfaces

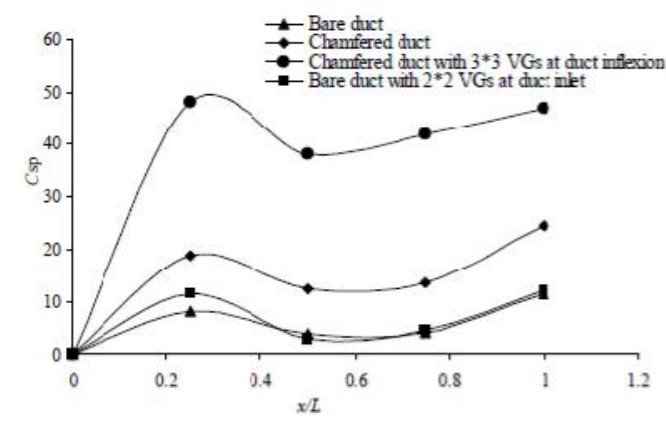

Fig. 9. Coefficient of static pressure recovery $\left(C_{\mathrm{SP}}\right)$.

The best configuration as shown in Fig. 9 has an agreement with the above discussion.

\subsection{Coefficient of Static Pressure Recovery $\left(C_{\mathrm{SP}}\right)$ and Total Pressure Loss $\left(C_{\mathrm{TL}}\right)$}

Coefficient of static pressure recovery $\left(C_{\mathrm{SP}}\right)$ and coefficient of total pressure loss $\left(C_{\mathrm{TL}}\right)$ are two important performance parameters of S-diffuser which are calculated as

$$
\begin{aligned}
& C_{\mathrm{SP}}=\left(p_{S}-p_{S i}\right) / p_{d} \\
& C_{\mathrm{TL}}=\left(p_{\mathrm{Ti}}-p_{\mathrm{T}}\right) / p_{d}
\end{aligned}
$$

$C_{\mathrm{SP}}$ is presented in Fig. 9 for all the combinations tested. The maximum $C_{\mathrm{SP}}$ reported is $48 \%$ for the rectangular duct with $45^{\circ}$ chamfered at all its corners and with $2 \times 2$ 'fishtail' VG installed at the inlet plane of the duct.

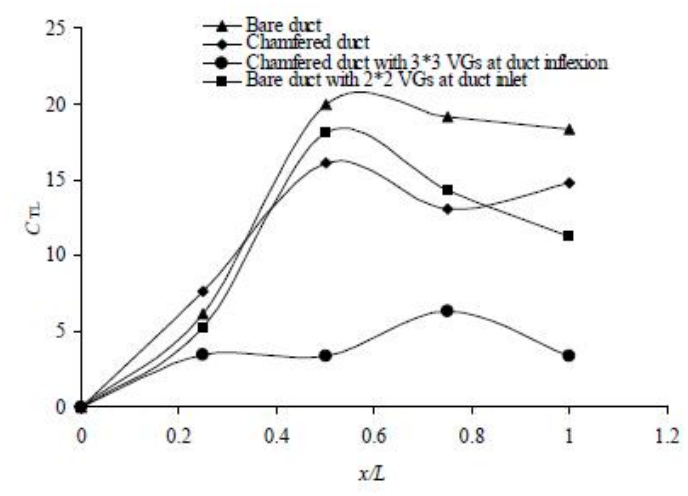

Fig. 10. Coefficient of total pressure loss $\left(C_{\mathrm{TL}}\right)$.
But the best configurations as suggested from the velocity and pressure contours (i.e., $45^{\circ}$ chamfered duct with $3 \times 3$ 'fishtail' VG fixed at the top and the bottom of the duct inflexion plane) reports the maximum $C_{\mathrm{SP}}$ of $48.57 \%$. Both these combinations have better values of $C_{\mathrm{SP}}$ as compared to that of bare duct. Coefficient of total pressure loss $\left(C_{\mathrm{TL}}\right)$ shows the similar variations as of $C_{\mathrm{SP}}$. The best configuration as reported above also represents minimum total pressure losses $(3.54 \%)$. It is seen from Figs. 9 and 10 that the variation of $C_{\mathrm{SP}}$ and $C_{\mathrm{TL}}$ are influences by the inflexion in the duct curvature.

\subsection{Distortion Coefficient with respect to The Worst $60^{\circ}$ Sector $\left(D C_{60}\right)$}

One of the most important parameters to judge the performance of the S-shaped diffuser is the distortion coefficient. It is defined as the following:

$$
D C_{60}=\left(p_{T e}-p_{60}\right) / p_{d}
$$

where, $p_{T e}$ is the total pressure at the duct exit (plane-5) and $p_{60}$ is the total pressure in the worst $60^{\circ}$ sector in respect to flow distortion. Table 1 furnishes $D C_{60}$ values for various conditions. The $3 \times 3 \mathrm{VG}$ at inflexion plane has the least $D C_{60}$ value of 0.141 . The $D C_{60}$ for the bare duct is 0.168 . Therefore, from the $D C_{60}$ value, it can be concluded that $3 \times 3 \mathrm{VG}$ at inflexion plane combination gives the best uniformity at the exit of the

\begin{tabular}{|c|c|}
\hline Case & $\mathrm{DC}_{60}$ \\
\hline Bare duct (with no VG) & 0.168 \\
\hline $45^{\circ}$ Chamfered bare duct & 0.155 \\
\hline $\begin{array}{l}\text { Chamfered duct with } 3 \times 3 \mathrm{VG} \text { at duct } \\
\text { inflexion (plane-5) }\end{array}$ & 0.141 \\
\hline $\begin{array}{l}\text { Bare duct with } 2 \times 2 \mathrm{VG} \text { at duct inlet } \\
\text { (plane-1) }\end{array}$ & 0.159 \\
\hline
\end{tabular}
S-duct diffuser.

Table 1 Distortion coefficient $\left(D C_{60}\right)$ for various

\section{Conclusion}

From the present investigation, the following conclusions can be drawn:

Chamfering of the duct corners improves the flow pattern to a large extent. But combining chamfering with 'fishtail' vortex generators (VG) installation may not be always fruitful as shown in this study, especially when the VG are installed at the duct inlet.

The newly designed 'fishtail' vortex generators, when used in reverse orientation, prove quite effective in controlling flow distortion at the duct exit. The geometry of the VG used in this case is simpler and 'easy to fabricate' as compared to 'wishbone' shaped VG earlier used by Sullery et al. (2004). 
From the experiment, it is revealed that the locations of the VG have a better influence on the flow pattern rather than the number of the VG used. Pressure difference present between any two opposite walls of the diffusers promotes bulk shifting of flow from one plane to other, especially at the exit plane of the diffuser.

The best combination examined in this report is a $45^{\circ}$ chamfered duct with 3-3 VG fixed at the top and bottom of the duct inflexion plane. The worst combination observed in this report was chamfered duct with a pair of VG installed each on top and bottom surfaces of the duct inlet plane.

Performance parameters- like coefficient of static pressure recovery $\left(C_{\mathrm{SP}}\right)$ and coefficient of total pressure loss $\left(C_{\mathrm{TL}}\right)$ for the best configurations (i.e., $45^{\circ}$ chamfered duct with $3 \times 3$ 'fishtail' VG fixed at the top and the bottom of the duct inflexion plane) are reported as $48.57 \%$ and $3.54 \%$ respectively.

The vortex generators presented in the paper is also able to reduce the engine-face distortion to an extent. With the best combination of $\mathrm{VG}$ reported in the paper, the $D C_{60}$ comes down from 0.168 (in case of bare duct) to 0.141 , i.e. $16 \%$ reduction in total pressure distribution is possible, which is reasonably higher than a $9 \%$ reduction with tapered-fin vortex generators reported by Sullerey et al. (2002).

\section{ACKNOWLEDGEMENTS}

The authors are grateful to Department of Science \& Technology, Govt. of India for providing necessary research infrastructure through DST-FIST grant. The financial assistance received from MNNIT, Allahabad is also acknowledged.

\section{REFERENCES}

Anderson, B.H., A. M.K.P. Taylor, J. Whitelaw and H. Yianneskis (1982). Developing flow in S-shaped ducts. In Proceedings of 2nd International Symposium on Application of LDA to Fluid Mechanics, Lisbon, Portugal.

Bakhtar, F., H. Mashmoushy and O.C. Jadayel (2001). Calibration characteristics of a three-hole probe and a static tube in wet steam. International J. of Heat and Fluid Flow 22, 537-542.

Dominy, R.G. and H.P. Hodson (1993). An investigation of factors influencing the calibration of five-hole probes for three-dimensional flow measurements. ASME J. of Turbomachinery 115, 513-519.

Foster, J., B.J. Wendt, B.A. Reichert and T.H. Okiishi (1997). Flow through rectangular-to-semi-annular diffusing transition duct. J. of Propulsion and Power 13 (2), 312-317.

Fox, R.W. and S.J. Kline (1962). Flow regimes in curved subsonic diffusers. Trans. ASME: Journal of Basic Engineering 84, 303-316.

Guo, R.W. and J. Seddon (1983). The swirl in an S-duct of typical air intake proportions. Aeronautical Quarterly 34, 99-129.

Harrison, N., J. Anderson, J.L. Fleming and F.N. Wing (2007). Experimental investigation of active flow control of a boundary layer ingesting serpentine inlet diffuser. AIAA Paper No. 2007-843.

Lin, Q. and R. Guo (1989). Vortex control investigation of swirl in S-shaped diffuser. Astronautica Sinica 10 (1), A35-A40.

Lin, J.C., G.V. Selby and F.G. Howard (1991). Exploratory study of vortex generating devices for turbulent flow separation control. AIAA Paper No. 91-0042.

Lin, J.C (2002). Review of research on low-profile vortex generators to control boundary-layer separation. Progress in Aerospace Sciences 38, 389-420.

Majumdar, B. (1994). Flow investigation in curved diffuser, $\mathrm{Ph}$. D. thesis, Indian Institute of Technology, Delhi, India.

Paul, A.R., K. Kalyan, N. Tripathi and T. Rajpathak (2008). Experimental and computational study of flow improvement through sigmoid air intake ducts using flow deflector. AIAA Paper No. 20087513.

Reichert, B.A. and B.J. Wendt (1993). An experimental investigation of S-duct flow control using arrays of low profile vortex generator. AIAA Paper No. 930018.

Reichert, B.A. and B.J. Wendt (1994). Improving diffusing S-duct performance by secondary flow control. NASA Technical Memorandum 106492.

Reichert, B.A. and B.J. Wendt (1996). Improving curved subsonic diffuser with vortex generators. AIAA Journal 34 (1), 65-72.

Seddon, J. and E.L. Goldsmith (1999). Intake Aerodynamics. AIAA Education Series, 2nd Edition, USA.

Stocks, C.P. and N.C. Bussinger (1981, May). The design and the development of Tornado engine airintake. In AGARD symposium on Aerodynamics of Power Plant installation.

Sullerey, R.K., S. Mishra and A.M. Pradeep (2002). Application of boundary layer fences and vortex generators in improving performance of S-duct diffusers. ASME J. of Fluids Engineering 124, 136-142.

Sullerey, R.K. and A.M. Pradeep (2004). Secondary flow control using vortex generator jets. ASME J. 
A.R. Paul et al. / JAFM, Vol. 4, No. 2, Issue 1, pp. 77-86, 2011

of Fluids Engineering 126, 650-657.

Sullerey, R.K. and A.M. Pradeep (2006). Active flow control in circular and transitioning S-duct diffusers. ASME J. of Fluids Engineering. 128, 1192-1203.

Wendt, B.J. and B.A. Reichert (1996). Vortex ingestion in a diffusing S-duct inlet. J. of Aircraft 33 (1), 149-154.

Weng, P.F. and R.W. Guo (1994). New method of swirl control in a diffusing S-duct. AIAA Journal 30 (7), 1918-1919.

Whitelaw, J. H. and S.C.M. Yu (1993) Turbulent flow characteristics in an S-shaped diffusing duct. Flow Measurements \& Instrumentation 3 (3), 171- 179. 